\title{
Representation of an Academic and Institutional Context Using Ontologies
}

\author{
Maricela Bravo ${ }^{1}$, Fernando Martínez-Reyes ${ }^{2}$, José Rodríguez $^{3}$ \\ ${ }^{1}$ Systems Department, Autonomous Metropolitan University, DF, Mexico \\ ${ }^{2}$ Faculty of Engineering, Autonomous University of Chihuahua, Chihuahua, Mexico \\ ${ }^{3}$ Computing Department, CINVESTAV-IPN, DF, Mexico \\ mcbc@correo.azc.uam.mx, fmartine@uach.mx,rodriguez@cs.cinvestav.mx
}

\begin{abstract}
In this paper we describe an ontology model that was designed and implemented to represent academic and institutional contexts related with a research center in Mexico City. The ontology model aims at supporting logicbased query answering and reasoning regarding contexts such as geographical areas, time, persons, libraries, cultural and academic events, teaching and tutoring schedules. The type of questions that the ontology model is capable of answering range from academic issues such as tutoring and thesis supervision; those concerning the location of people, libraries, buildings, roads; those regarding time such as class schedules, event schedules; and even those about the food menu offered at the cafeteria of the institution. In order to evaluate the ontology model, a set of competency questions were translated into SQWRL rule-based query language. Results of queries show the feasibility of using ontological models as the supporting technology to implement ubiquitous and pervasive systems for academic environments.
\end{abstract}

Keywords: Ontology models, academic contexts, recommendation system.

\section{Introduction}

Currently academic institutions and research centers manage large amounts of data concerning their academic and research activities, cultural events and services, and personnel. Such information must be available for students, professors, administration staff and visitors. The management of large amounts of data represents an opportunity for the adoption of Semantic Web Technologies. The literature shows a clear trend in the use of ontologies for knowledge management and information sharing systems that manage the context, such as: recommendation systems based on context, context- aware systems, context-adaptive systems [1, 2, 3], to name a few. Furthermore, several studies have reported on the use of ontologies for handling and representing contexts $[4,5,6$, 7]. In this paper we describe the design and implementation of an ontological model for an academic and institutional context. The system offers a logic-based content provider for the answering of academic issues such as tutoring and thesis supervision; those 
concerning the location of people, libraries, buildings, roads; those regarding time such as class schedules and event schedules. Furthermore, the ontology's services are made available for mobile devices in order to take into account the users' mobility.

The rest of the paper is organized as follows: Section 2 presents our motivation; Section 3 describes the particular contextual models that support the institutional ontology model, and its integration as a web service; Section 4 presents an evaluation of the ontology model based on the defined competency questions, and the user interfaces built to accomplish this task; and finally in section 5 conclusions are presented.

\section{Motivation}

Over the last decades we have witnessed different research venues for semantic web technologies. Of particular attention is the growing community promoting and adopting the use of ontologies as the instrument for modeling contextual information. For example, an ontology model was developed for home health monitoring [8] especially for patients that need to stay at home, and under the continuous supervision of a care network (e.g. family members, doctors, nurses and the care center). The system provides access to the ambient and biomedical sensing data, the contextual representation of the patient health status, and possible health-care plans. Another interesting application for ontologies is proposed in MAIS [9], implemented for the context of tourist services which enable users to design their tour plans, schedule itineraries and be aware of transportation routes all over the same platform. An ontology model that takes into account location is $\mathrm{mIO}$ [10], designed to explore interoperability in a net- worked environment where, for example, content, services, connectivity and accessibility can vary among users' profile and their location.

Ontology models thus can help characterize and specify all of the entities needed to describe the context as a whole [11]. A context can be composed for contextual items such as location, physical data, activity, and instrumental and social context [12]. By means of ontologies it is possible to model an explicit specification of what users' needs and offer back the level of information and services that would support individuals' everyday activities [13],[14]. The set of ontology models described in this paper were designed to represent contexts such as geographical areas, time, persons, libraries, cultural and academic events, teaching and tutoring schedules.

\section{An Ontology Model for Academic and Institutional Context}

In this section we describe the set of contextual models that together integrate the top level ontology which in turn support the web service available for professors, students, administration staff and visitors. The main objective of this ontological model was to provide a prototype implementation to show the advantages and conveniences of ontology-based solutions for ubiquitous computing and pervasive systems. In particular, we aim in providing a knowledge-based system to support student lifestyle inside the campus. It is important to note that the ontology model was implemented in 
Spanish language. On its own each ontology model represents a sub-domain of the contextual environment, i.e. institutional resources, facilities and services. The main ontology, integrating low level models, can be queried for information regarding zones/spaces, individuals, academic and no academic events and buildings.

Geographic Area Ontology. This ontology model seeks to provide contextual information about the physical resources and facilities students would like to use or know about. For example, as they arrive to the institution premises they can query the system for the different zones used for parking lots (estacionamiento).

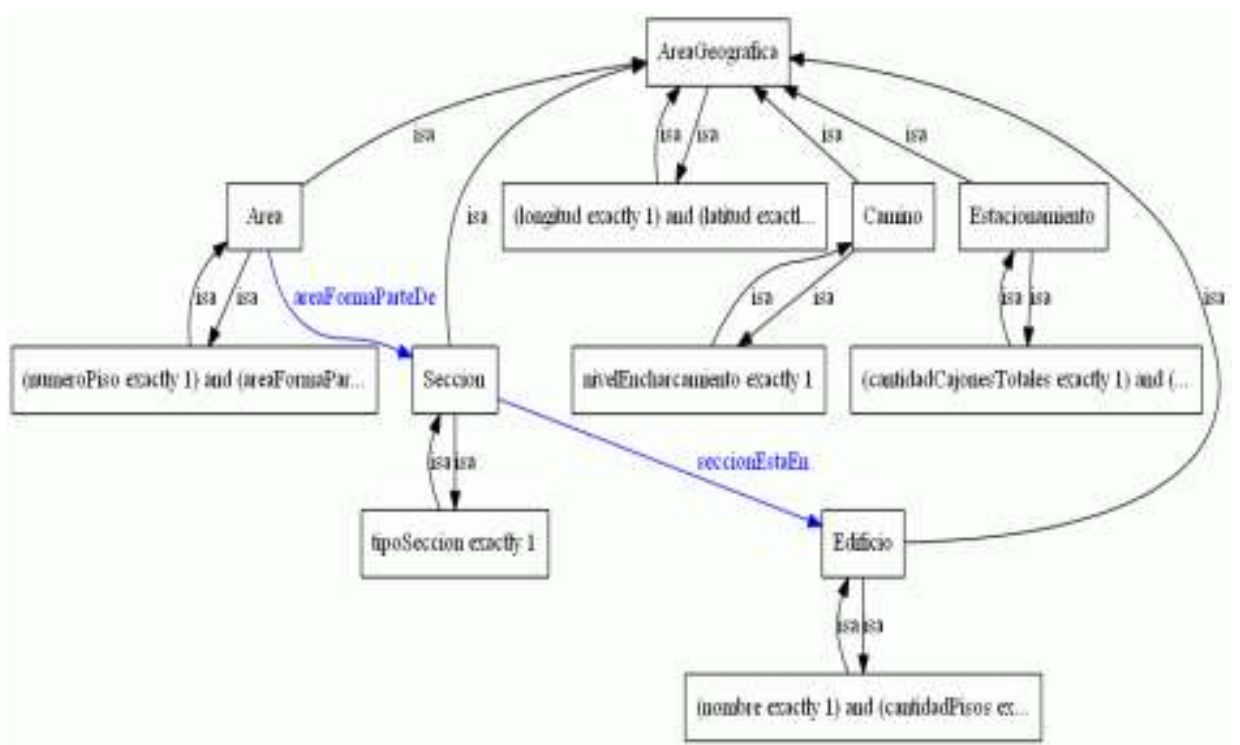

Fig. 1. Geographic area ontology model.

There is an ontology model for main buildings (edificio) and another one (areas) for the different sub-divisions exists inside buildings, e.g. professors' offices, tutoring cubicles, student counseling, among others. Other buildings' spaces that are occasionally used by students, e.g. toilets, conference rooms and administration offices are modeled into a section's ontology (sección). In order to facilitate the location of physical facilities there is available an ontology model for paths (camino). As can be observed from Figure 1, any physical facility has a longitude and latitude (GPS landmark) property.

Person Ontology. The Person ontology (Figure 2) aims at representing individuals that are part of the institution, or that are visitors. The class Person is axiomatically described as follows: every person must have exactly one name, every person must have exactly one gender, every person must have exactly one date of birth, every person must have exactly one age, and every person must have at least one nationality. The student class (alumno) is used to represent individuals that may be of two classes: MSc 
degree students and PhD students. With an employee class (empleado) we defined academic, teachers and researchers, and administration staff. There is also a class to take into account visitors, no matter for how long these individuals would stay at the institution.

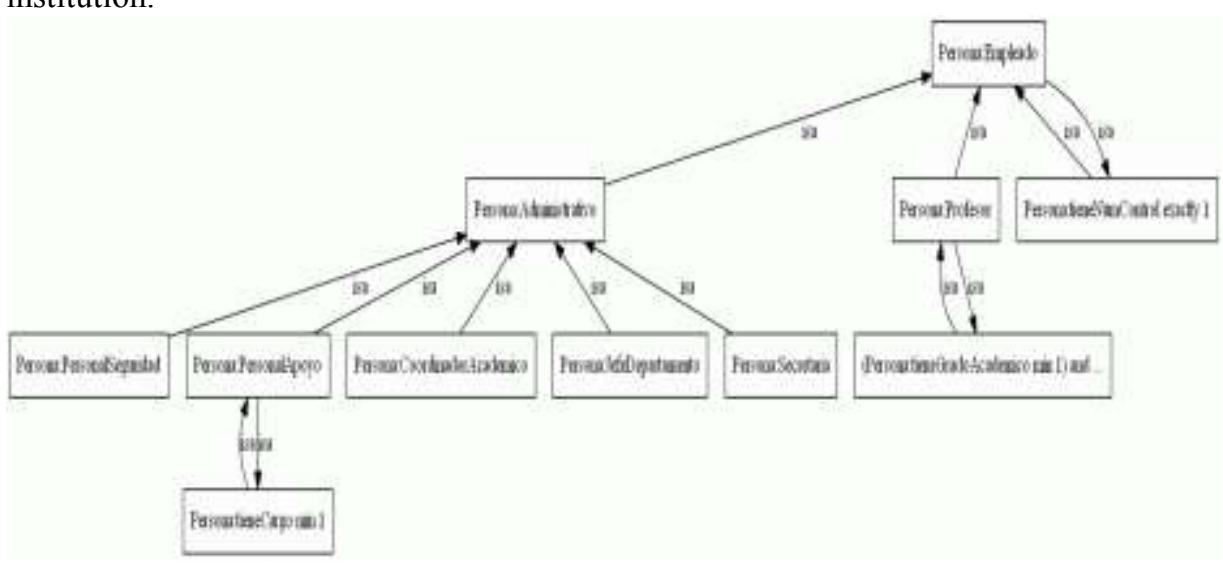

Fig. 2. Person ontology model.

Academic Ontology. This model is used to provide information about the courses or subjects being offered by the institution. Classes contextualizing this ontology include the subject (materia), its timetabling, and the professor teaching that particular course. For the sake of space in Figure 3 is offered an extract of the relationships existing between the academic, person and geographic ontologies, highlighting their object properties.

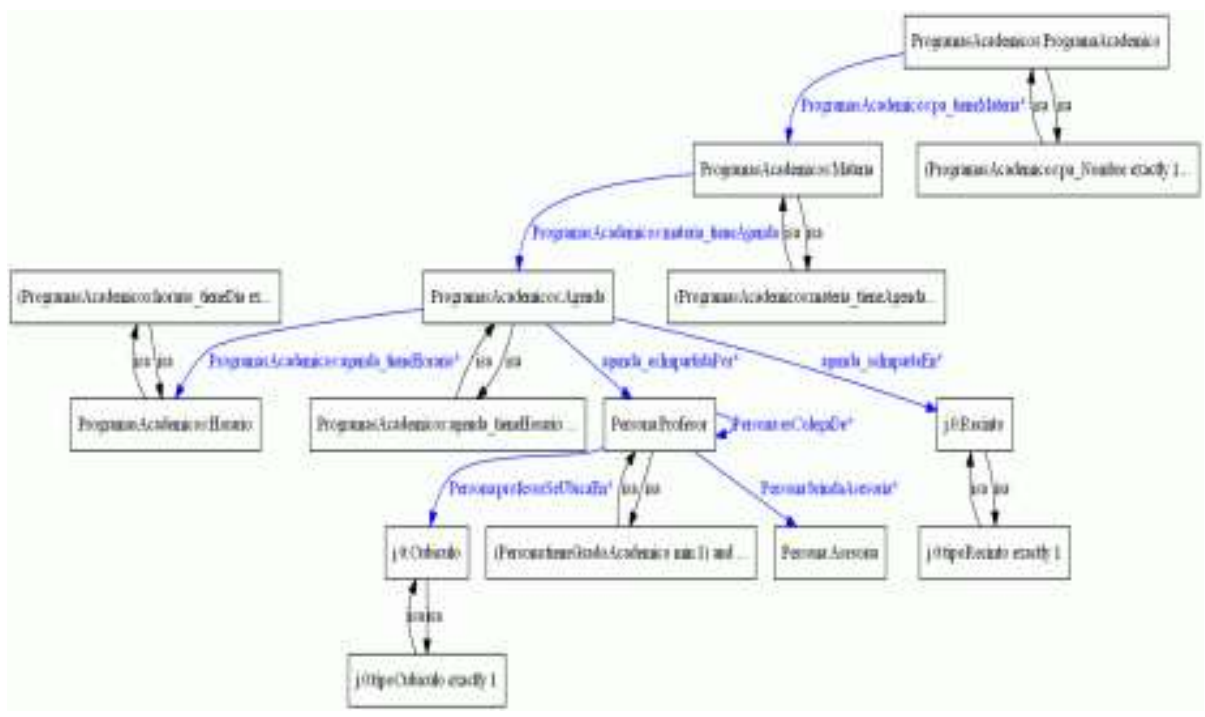

Fig. 3. Semantic relationships between the ontologies Academic, Person and Geographic Area. 
As indicated in Figure 3, object properties are important in order to link concepts between ontologies and to support query answering. In particular, the following object properties are of special interest:

- agenda_tieneHorario. This object property has as domain the ProgramasAcademicos:Agenda class and as a range the ProgramasAcademicos:Horario class. This object property is used to create academic program schedules, associating the time with the subject name of the course.

- agenda_seImparteEn. This object property has as domain the ProgramasAcademicos:Agenda class and as a range the Recinto class. This object property is used to specify the specific classroom where the course is to be taught.

- agenda_esImpartidaPor. This object property has as domain the ProgramasAcademicos:Agenda class and as a range the Persona:Profesor class. This object property is used to specify the professor responsible of teaching the course.

Other Contextual Ontologies. There are two additional academic ontologies aiming at supporting academic, sports or cultural events. For instance, the events calendar ontology helps users to be aware of what events either academics, sports or cultural, are programmed in the institution calendar, so they cannot miss a single one. In addition, the library ontology model is used to rep- resent the library and the services it offers such as book titles and the number of items that are available for lending. There is also the "Ontology Area" which helps for location of the different sub-divisions exists inside buildings, e.g. professors' offices, tutoring cubicles and student counseling, among others. An "Ontology Cafeteria" offers information about its daily menu.

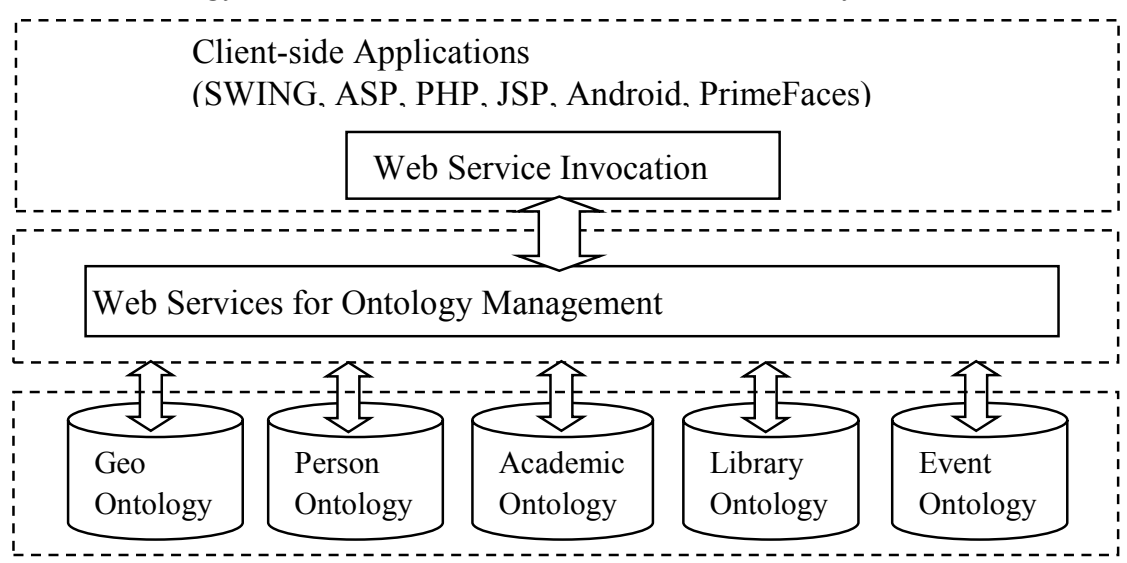

Fig. 4. Architecture for Academic and Institutional Context.

Finally, in Figure 4 we present the three tier architecture which incorporates the ontology layer, the services layer and the client-side applications. As describe above the ontology layer consists of seven ontology models that together provide the semantic 
concepts and relations for the set of Web services that are invoked from user's client applications, introduced in the evaluation section.

\section{Evaluation}

The main contribution of this research relies on the system ontology design for the representation of an institutional context in order to support users with information about individuals, buildings, events, and other academic related resources. In order to enable the ontology model answer the contextual questions made by users a set of SWRL rules supporting the reasoning level of the ontology were implemented. Table 1 presents some of the SQWRL rules that met some of the competency questions defined for the institutional model.

Table 1. Competency questions and their respective SQWRL query rule.

\begin{tabular}{|c|c|c|}
\hline $\begin{array}{l}\text { tency } \\
\text { tion }\end{array}$ & in & $\mathbf{y}$ \\
\hline $\begin{array}{l}\text { How many } \\
\text { articles has } \\
\text { Dr. } \quad \mathrm{X} \\
\text { published? }\end{array}$ & $\begin{array}{l}\text { ing up } \\
\text { strong } \\
\text { ch }\end{array}$ & $\begin{array}{l}\text { Persona:Profesor(?p) } \wedge \text { Persona:tieneNombre(?p, ?y) } \wedge \\
\text { swrlb:stringEqualIgnoreCase(?y, "Amilcar Meneses Viveros") } \\
\text { Persona:tieneArticulosPublicados(?p, ?cantidad) } \\
\text {-> sqwrl:select(?cantidad) }\end{array}$ \\
\hline $\begin{array}{l}\text { How many } \\
\text { students } \\
\text { graduated in } \\
\text { area } X ?\end{array}$ & $\begin{array}{l}\text { I would like } \\
\text { to go for a } \\
\text { successful } \\
\text { career. }\end{array}$ & $\begin{array}{l}\text { Persona:Alumno(?x) } \quad \text { Area:Area(?area) } \\
\text { Area:tieneNombre(?area, } \\
\text { swrlb:stringEquallgnoreCase(?nombre, } \\
\text { "PruebaConSistemasDistribuidos YParalelos") } \\
\text { Persona:estudiaEn(?x,?area) } \\
\text {-> sqwrl:select(?x) }\end{array}$ \\
\hline $\begin{array}{l}\text { Where is the } \\
\text { office of } \\
\text { Professor X? }\end{array}$ & $\begin{array}{l}\text { I would like } \\
\text { to talk to a } \\
\text { professor } \\
\text { who may } \\
\text { agree to be } \\
\text { my thesis's } \\
\text { supervisor. }\end{array}$ & $\begin{array}{l}\text { Persona:Persona(?p) } \wedge \text { Persona:tieneNombre(?p, "Amilcar } \\
\text { Meneses Viveros") } \wedge \text { seEncuentraEn(?p,?areaGeografica) } \\
\text { GeographicArea:areaFormaParteDe(?areaGeografica,?seccion) } \\
\text { GeographicArea:tipoSeccion(?seccion,?tipoSeccion) } \\
\text { GeographicArea:seccionEstaEn(?seccion,?edificio) } \\
\text { GeographicArea:nombre(?edificio,?nombreEdificio) } \\
\text {-> sqwrl:select(?tipoSeccion,?nombreEdificio) }\end{array}$ \\
\hline $\begin{array}{l}\text { Is the book } X \\
\text { in the library } \\
Y \text { ? }\end{array}$ & $\begin{array}{l}\text { I need to } \\
\text { find } \\
\text { literature } \\
\text { resources to } \\
\text { complete } \\
\text { assignments } \\
\end{array}$ & $\begin{array}{l}\text { Biblioteca:Biblioteca(?y) } \wedge \text { Biblioteca:Libro(?x) } \\
\text { Biblioteca:tieneLibro(?y,?x) } \\
\text { Biblioteca:Nombre(?x,"Sustainability in the Chemical Industry") } \\
\text { Biblioteca:NombreBiblioteca(?y,"Biblioteca de Química") } \\
\text {-> sqwrl:select(?x) }\end{array}$ \\
\hline $\begin{array}{l}\text { Where is the } \\
\text { cubicle of } \\
\text { person } \mathrm{X} \\
\text { located? }\end{array}$ & $\begin{array}{l}\text { I would like } \\
\text { to talk to } \\
\text { students } \\
\text { working on }\end{array}$ & $\begin{array}{l}\text { Persona:Persona(?p) } \wedge \text { Persona:tieneNombre(?p, "Marco Antonio } \\
\text { Castro Hernandez") } \wedge \quad \text { GeographicArea:Cubiculo(?c) } \\
\text { ocupadaPor(?c, } \\
\text { GeographicArea:tipoCubiculo(?c,?tipoCubiculo)^ }\end{array}$ \\
\hline
\end{tabular}


Representation of an Academic and Institutional Context using Ontologies

\begin{tabular}{|l|l|lr|}
\hline $\begin{array}{c}\text { Competency } \\
\text { Question }\end{array}$ & $\begin{array}{l}\text { Context of } \\
\text { interest }\end{array}$ & \multicolumn{1}{|c|}{ SWRL Query } \\
\hline & $\begin{array}{l}\text { research } \\
\text { areas that }\end{array}$ & $\begin{array}{l}\text { GeographicArea:areaFormaParteDe(?c,?seccion) } \\
\text { GeographicArea:Seccion(?seccion) }\end{array}$ & $\wedge$ \\
& $\begin{array}{l}\text { are of my } \\
\text { interest. }\end{array}$ & GeographicArea:seccionEstaEn(?seccion,?edificio) & $\wedge$ \\
& & GeographicArea:Edificio(?edificio) & $\wedge$ \\
& & GeographicArea:nombre(?edificio,?nombreEdificio) & \\
\hline \multirow{4}{*}{$\begin{array}{l}\text { How many } \\
\text { places are }\end{array}$} & Hope I can & GeographicArea:Estacionamiento(?e) & \\
available for a & luckily find & GeographicArea:cantidadCajonesTotales(?e, ?cTotales) & $\wedge$ \\
particular & a slot in the & GeographicArea:cantidadCajonesOcupados(?e, ?cOcupados) & $\wedge$ \\
parking lot? & car parking. & swrlb:subtract(?cDisponibles, ?cTotales, ?cOcupados) & $\wedge$ \\
& & descripcionEstacionamiento(?e,?desc) & \\
\hline
\end{tabular}

The ontology model was evaluated using both computer and mobile interfaces. Users can interact with these interfaces to ask questions without having to hassle with edition and execution of SWRL rules. Figure 5 shows some of the questions posted to the ontology model and their correspondent response.

An Android based interface was built to take into account user mobility. Figure 6 presents how the user queries the ontology model to ask for the location of an individual. In Figure 6a, a student issued the query to ask for a teacher's office. S/he first selects the object person (persona) of type teacher (professor) and by leaving the teacher's office instructs the ontology to return this information. Figure $6 \mathrm{~b}$, shows that the ontology model by means of the web service returns the full name of the teacher, its office and the building this is in.

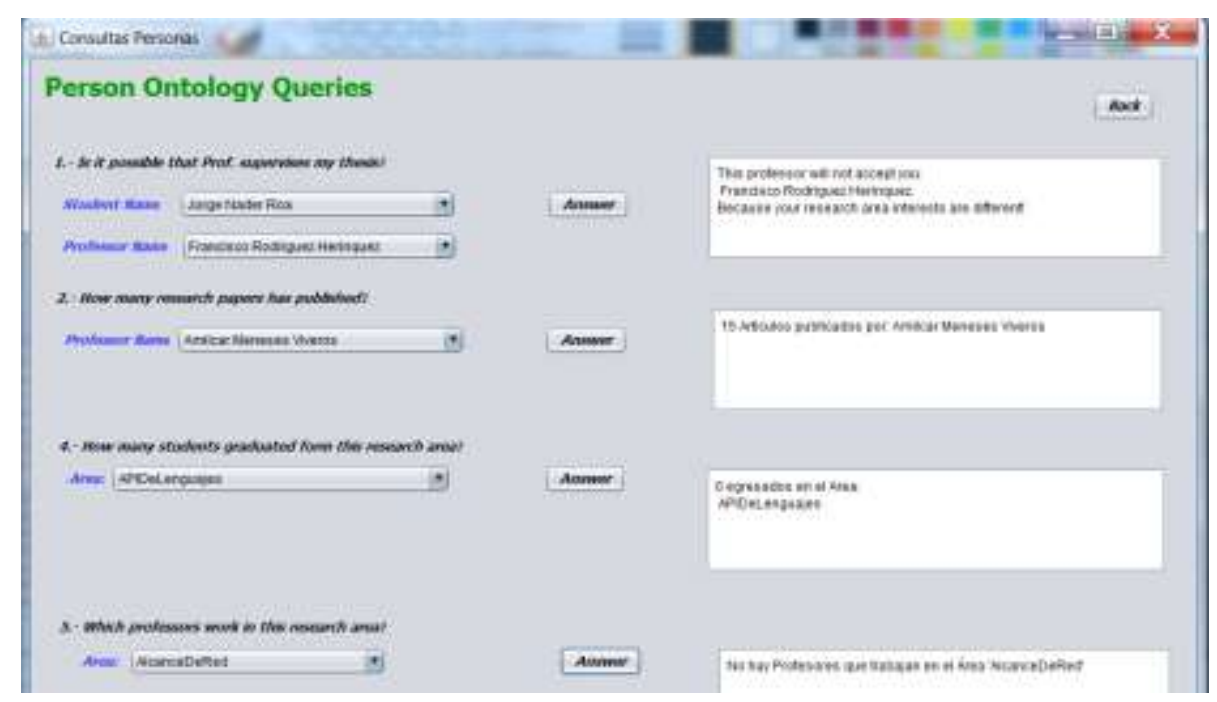

Fig. 5. Java based client to evaluate the ontology model performance. 

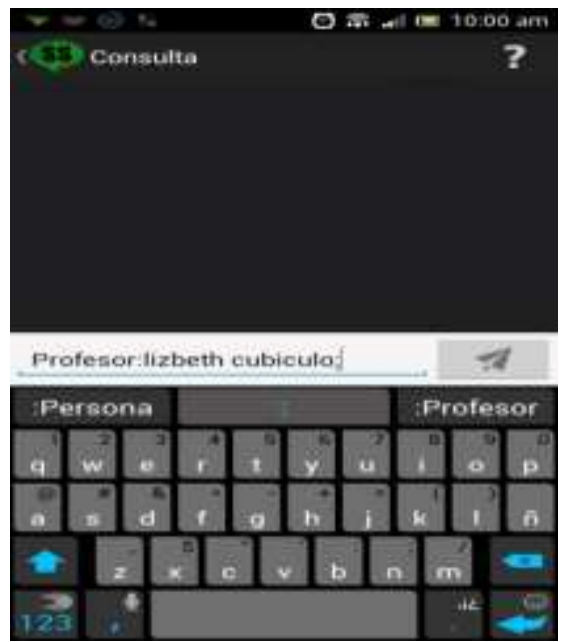

Fig. 6. The user asks the institutional ontology for the office of a teacher.

\section{Conclusions}

In this paper we have presented an ontology model that was designed and implemented to represent academic and institutional contexts. In terms of student support the ontology model is capable of answering location and resources/facilities issues. For example, students can get information about the office and classroom the professors is in. They can also identify where buildings, libraries, administration offices are, and what are the routes leading to these institution's spaces. Moreover, users can be aware of the academic (e.g. seminars) and not academic (e.g. sports) events. Ontologies represent a key enabler for context-aware systems, as they enable concept and knowledge sharing while providing a model for context reasoning and query answering. We have evaluated the usefulness of the ontological model through the definition of competency questions and the implementation of an Android application to facilitate the user interaction with the ontology model.

\section{References}

1. Want, R., Hopper, A., Falcao, V., Gibbons, J.: The Active Badge Location System. In: ACM Transactions on Information Systems, vol. 10(1), pp. 91-102 (1992)

2. Abowd, G.D., Atkerson, C.G., Hong, J., Long, S., Kooper, R., Pinkerton, M.: Cyberguide: A Mobile Context-Aware Tour Guide. In: Wireless Networks, vol. 3(5), pp. 421-433 (1997)

3. Cheverst, K., Davies, N., Mitchell, K., Friday, A., \& Efstratiou, C.: Developing a ContextAware Electronic Tourist Guide: Some Issues and Experiences. In: Proceedings of the SIGCHI conference on Human factors in computing systems, pp. 17-24 (2000)

4. Henricksen, K., Indulska, J., \& Rakotonirainy, A.: Modeling context information in pervasive computing systems. In: Pervasive Computing, pp. 167-180. Springer Berlin Heidelberg (2002) 
5. Henricksen K., \& Indulska J.: Developing context-aware pervasive computing applications: Models and approach. In: Pervasive and Mobile Computing, Elsevier (2005)

6. Chen H., Finin T., \& Joshi A.: An ontology for context-aware pervasive computing environments. In: Special Issue on Ontologies for Distributed Systems, Knowledge Engineering Review, Acapulco, Mexico (2003).

7. Wang X., Zhang D. Q., Gu T., \& Pung H. K.: Ontology Based Context Modeling and Reasoning using OWL. In: Workshop on context modeling and reasoning at IEEE International Conference on Pervasive Computing and Communication, Orlando, Florida (2004)

8. Paganelli, F., \& Giuli, D.: An Ontology-Based Context Model for Home Health Monitoring and Alerting in Chronic Patient Care Networks. In: AINA Workshops (2) pp. 838-845 (2007)

9. Chiu, D. K., Yueh, Y. T., Leung, H. F., \& Hung, P. C.: Towards ubiquitous tourist service coordination and process integration: A collaborative travel agent system architecture with semantic web services. In: Information Systems Frontiers, vol. 11(3), pp. 241-256 (2009)

10. Poveda Villalon, M., Suárez-Figueroa, M. C., García-Castro, R., \& Gómez-Pérez, A.: A context ontology for mobile environments (2010)

11. Devaraju, A., \& Simon H.: Ontology-based context modeling for user-centered contextaware services platform. In: Information Technology, 2008. ITSim 2008. International Symposium on, vol. 2, pp. 1-7. IEEE, (2008)

12. Paganelli, F., Bianchi, G., \& Giuli, D.: A context model for context-aware system design towards the ambient intelligence vision: experiences in the eTourism domain. In: Universal access in ambient intelligence environments, pp. 173-191. Springer Berlin Heidelberg (2007)

13. Chen, G., \& Kotz, D.: A survey of context-aware mobile computing research, vol. 1, No. 2.1. Technical Report TR2000-381, Dept. of Computer Science, Dartmouth College (2000)

14. Gruber, T. R.: A Translation approach to portable ontologies. Knowledge Acquisition, vol. 5(2), pp. 199-220 (1993) 